\title{
Human rights and access to healthcare services for indigenous peoples in Africa
}

\author{
Ebenezer Durojaye
}

\begin{abstract}
In September 2015, the United Nations adopted the sustainable development goals (SDGs) to address among others poverty and inequality within and among countries of the world. In particular, the SDGs aim at ameliorating the position of disadvantaged and vulnerable groups in societies. One of the over-arching goals of the SDGs is to ensure that no one is left behind in the realisation of their access to health care. African governments are obligated under international and regional human rights law to ensure access to healthcare services for everyone, including indigenous populations, on a non-discriminatory basis. This requires the governments to adopt appropriate measures that will remove barriers to healthcare services for disadvantaged and marginalised groups such as indigenous peoples.
\end{abstract}

\section{Introduction}

We should ensure that no person - regardless of ethnicity, gender, geography, disability, race or other status - is denied universal human rights and basic economic opportunities. We should design goals that focus on reaching excluded groups. ${ }^{1}$

According to the preamble to the Universal Declaration on Human Rights, 'the inherent dignity and of the equal and inalienable rights of all members of the human family is the foundation of freedom, justice and peace in the world'. ${ }^{2}$ This makes it imperative for African governments to adopt a rights-based approach to realising access to healthcare services for indigenous peoples in the region. An estimated 370 indigenous peoples are said to be living in 90 countries across the world. Indigenous peoples face serious challenges in different areas of their lives (United Nations, 2014). Due to historical disadvantage and social exclusion, indigenous peoples often encounter challenges in accessing healthcare services in many parts of Africa. While the term 'indigenous peoples' has remained contested and without universally acceptable definition, attempts have been made to give a generous interpretation of this term. Thus, indigenous peoples have been defined to include peoples who:

- Identify themselves and are recognised and accepted by their community as indigenous.

- Demonstrate historical continuity with pre-colonial and/or pre-settler societies.

- Have strong links to territories and surrounding natural resources.

- Have distinct social, economic or political systems. 
- Maintain distinct languages, cultures and beliefs.

- Form non-dominant groups of society.

- Resolve to maintain and reproduce their ancestral environments and systems as distinctive peoples and communities. 3

The African Commission on Human and Peoples' Rights (ACHPR) Working Group on Indigenous Populations/Communities is of the view that, a definition is not necessary or useful as there is no universally agreed definition of the term and no single definition can capture the characteristics of indigenous populations (African Commission on Human and Peoples' Rights, 2005). 4 Thus, the major characteristics, which allow the identification of Africa's Indigenous Communities is the favoured approach. The concept in effect embodies the following constitutive elements or characteristics, among others

- Self-identification;

- A special attachment to and use of their traditional land whereby their ancestral land and territory have a fundamental importance for their collective physical and cultural survival as peoples;

- A state of subjugation, marginalisation, dispossession, exclusion, or discrimination because these peoples have different cultures, ways of life or mode of production than the national hegemonic and dominant model (African Commission on Human and Peoples' Rights, 2005; Ako \& Oluduro, 2014).

It is noted further that in Africa, the term 'indigenous populations' does not mean 'first inhabitants' in reference to aboriginality as opposed to non-African communities or those having come from elsewhere. This peculiarity distinguishes Africa from the other continents where native communities have been almost annihilated by non-native populations. Therefore, the ACHPR considers that any African can legitimately consider him/herself as indigene to the continent. The fact remains, however, that the notion of self-determination has evolved with the development of the international visibility of the claims made by indigenous populations whose right to self-determination is exercised within the standards and according to the modalities which are compatible with the territorial integrity of the Nation States to which they belong.

While the use of the term 'indigenous peoples' has remained subject of contestation in Africa, it should be noted that indigenous peoples face various forms of human rights violations, particularly in relation to healthcare services. Based on the above criteria, it may be argued that the Ogonis, San, Masai, Twa, Batwa and Koisans, are examples of indigenous peoples in Africa.

In many African countries, the right to health of indigenous population has not received the attention of the governments. Thus, health policies and programmes are often developed that do not meet the needs of indigenous peoples. Apart from the fact that indigenous peoples have worse health indicators than non-indigenous populations, they 
also lack access to health services that can improve their health and well-being. Persistent inequities in the health status of indigenous peoples tend to compromise their well-being (United Nations, 2014). One of the over-arching goals of the sustainable development goals (SDGs) is to ensure that no one is left behind in the realisation of their access to health care. The SDGs recognise that vulnerable groups, including indigenous peoples must be given special attention and empowered to live a meaningful life (United Nations, 2015). Specifically, goal 3 aims at ensuring healthy lives and promoting well-being for all ages. The international community further agrees to ensure universal access to healthcare services for all and that no one should be left behind in this regard. One of the targets for goal 3 is to achieve 'access to quality essential healthcare services and access to safe, effective, quality and affordable essential medicines and vaccines for all' (United Nations, 2015, target 3.8). More importantly, the international community agrees to 'accelerate the pace of progress made in fighting malaria, HIV/ AIDS, tuberculosis, hepatitis, Ebola and other communicable diseases and epidemics, including by addressing growing antimicrobial resistance and the problem of unattended diseases affecting developing countries' (United Nations, 2015: para 26).

African governments are obligated under international and regional human rights law to ensure access to healthcare services for everyone, including indigenous populations, on a non-discriminatory basis. This requires the governments to adopt appropriate measures that will remove barriers to healthcare services for disadvantaged and marginalised groups such as indigenous peoples.

According to the preamble to the Universal Declaration on Human Rights, 'the inherent dignity and of the equal and inalienable rights of all members of the human family is the foundation of freedom, justice and peace in the world'. 5 This makes it imperative for African governments to adopt a rights-based approach to realising access to healthcare services for indigenous peoples in the region.

\section{The right to health of indigenous peoples}

Indigenous peoples, like every individual, are entitled to the enjoyment of the highest attainable standard of physical and mental health. Although, there is no specific binding human rights instruments dealing with the rights of indigenous peoples, several provisions of human rights instruments can be invoked to advance the right to health of indigenous peoples. The right to the highest attainable standard of physical and mental health is guaranteed in most of UN human rights instruments such as the International Covenant on Economic, Social and Cultural Rights (ICESCR), ${ }^{6}$ Convention on Elimination of All Forms of Discrimination against Women, 7 the Convention on the Rights of Child 8 and Convention on the Rights of Persons with Disabilities.9 All these instruments contain provisions requesting states to respect, protect and fulfil the right to health of every individual including indigenous peoples. The most authoritative provision on the right to health is found in article 12 of the ICESCR. It guarantees everyone the right to the enjoyment 
of highest attainable standard of physical and mental health. It also recognises the importance of the underlying determinants of health.

In its General Comment 14, the Committee on Economic, Social and Cultural Rights (CESCR) has explained that the right to health encompasses both freedoms and entitlements. ${ }^{10}$ While 'freedoms' implies that no individual should be forced to undergo medical treatment without informed consent, 'entitlements' refers to access to healthcare facilities, goods and services. The right to health does not imply that states must ensure that everyone one is healthy, however, it does places obligations on a state to ensure that it creates an enabling environment that will facilitate access to health care for all. The CESCR notes that the right to health contains four essential elements namely; availability, accessibility, acceptability and quality. How these elements apply to indigenous peoples are explored later in this article. The Committee further notes that the enjoyment of the right to health is dependent on other rights such as equality and non-discrimination, dignity, privacy and life.

While the CESCR recognises that the right to health may be realised progressively, it however, notes that the minimum core contents of the right are not subject to progressive realisation The Committee identifies the principle of non-discrimination as one of the core contents of the right to health which must be realised immediately. In the Committee's view, states are obligated to ensure the provision of healthcare services to all on a nondiscriminatory basis paying attention to the needs of vulnerable and marginalised groups in society. The CESCR also stated that indigenous peoples have the right to specific measures to improve their access to health services and care ... States should provide resources for indigenous peoples to design, deliver and control such services so that they may enjoy the highest attainable standard of physical and mental health'. ${ }^{11}$ Also, States have the obligations to respect, protect and fulfil the right to health of all as guaranteed in the ICESCR. The relevance of these obligations to indigenous peoples is discussed below. More recently, the Committee in its General Comment 22 on sexual and reproductive health has urged states to ensure universal access to sexual and reproductive care services to all individuals, including vulnerable and marginalised groups such as indigenous peoples. ${ }^{12}$

The UN Special Rapporteur on the right of everyone to the enjoyment of the highest attainable standard of physical and mental health (2006) has noted that the enjoyment of the right to health can be understood as a right to an effective and integrated health system, encompassing health care and the underlying determinants of health, which is responsive to national and local priorities, and accessible to all. In one of his recent reports, the Special Rapporteur (2016, p. 41) has noted that achieving the overarching goal of the SDGs of leaving no one behind 'requires a foundational shift in implementation, one that prioritises those furthest behind, identifies and gives visibility to those populations, understands the barriers to their exclusion and establishes mechanisms and policies to enable their inclusion and empowerment'. 
In addition to these binding instruments, the international community has developed important norms and standards affirming the right to health of indigenous peoples. For instance, article 21 of the UN Declaration on Indigenous Peoples notes that indigenous peoples have the right without discrimination to the enjoyment of socioeconomic rights, including water, sanitation and health. ${ }^{13}$ Moreover, article 24 provides that indigenous peoples shall have equal right to the enjoyment of the right to highest attainable standard of physical and mental health. Also, article 25 of ILO Convention 169 specifically guarantees the right to health of indigenous peoples by stating that 'Governments shall ensure that adequate health services are made available to the peoples concerned'. It further notes that healthcare services for indigenous peoples shall be 'planned and administered in cooperation with the peoples concerned and take into account their economic, geographic, social and cultural conditions as well as their traditional preventive care, healing practices and medicines'. ${ }^{14}$ These provisions reflect international commitments to realise the right to health of indigenous peoples. As part of protecting the human rights of indigenous peoples across the world, the UN Human Rights Council in 2000 established the UN Permanent Forum on Indigenous Peoples. This body serves in advisory capacity to the Council on issues relating to economic and social development, culture, the environment, education, health and human rights of indigenous peoples. ${ }^{15}$

At the regional level, the three major human rights instruments - the African Charter on Human and Peoples' Rights (African Charter), ${ }^{16}$ the African Charter on the Rights and Welfare of the Child ${ }^{17}$ and the Protocol to the African Charter on the Rights of Women (African Women's Protocol) - all contain useful provisions on the right to health that can be invoked to apply to the needs of indigenous peoples. Specifically, article 16 of the African Charter guarantees the right to health of all individuals, while article 14 of the African Women's Protocol guarantees women's right to health care, including sexual and reproductive health. The rights to equality and non-discrimination are crucial in realising access to healthcare services for vulnerable and marginalised groups such as indigenous peoples. Thus, the African Commission has emphasised that the provisions on equality and non-discrimination in articles 2 and 3 of the African Charter are crucial to the enjoyment of all other rights in the Charter. ${ }^{18}$ It is also important to note the that the African Commission has a Working Group on Indigenous Populations/Communities as one of its special mechanisms to focus on the human rights challenges facing indigenous peoples in the region. ${ }^{19}$ While the Working Group has documented human rights violations experienced by indigenous peoples, it is yet to conduct a comprehensive study on the challenges relating to the enjoyment of the right to health of indigenous peoples.

\section{Barriers to health services for indigenous peoples in Africa}

Across the world, the health status of indigenous peoples differs greatly from those of nonindigenous populations. It has been noted that the persistent commonality among indigenous peoples across the globe is inequities in access to healthcare services compared to nonindigenous populations (United Nations, 2014). This does not only affect their health status 
but also the social determinants of health. The Inter-Agency Support Group on Indigenous Peoples' Issues (2014, p. 1) has noted as follows:

Data indicates that circumstances of extreme poverty are significantly more prevalent among indigenous peoples than non-indigenous groups, and are rooted in other factors, such as a lack of access to education and social services, destruction of indigenous economies and socio-political structures, forced displacement, armed conflict, and the loss and degradation of their customary lands and resources. These forces are determined and compounded by structural racism and discrimination, and make indigenous women and children particularly vulnerable to poor health. Because of these phenomena, indigenous peoples experience high levels of maternal and infant mortality, malnutrition, cardiovascular illnesses, HIV/AIDS and other infectious diseases such as malaria and tuberculosis.

Ohenjo et al. (2006) have documented the healthcare challenges indigenous peoples encounter in Africa. Using the central African Pygmy and San as case studies, they present a detailed study of the health challenges among indigenous peoples in Africa. According to the authors, lack of attention and political will on the part of African governments has led to lack of healthcare facilities and consequently poor health outcome among indigenous peoples (Ohenjo et al., 2006). It is noted that discriminatory practices against indigenous peoples tend to aggravate the right of indigenous peoples to healthcare services. In particular, the study shows that mortality and fertility rates among indigenous peoples tend to be higher than non-indigenous populations in many African countries. This is occasioned by lack of comprehensive healthcare services for indigenous populations (Ohenjo et al., 2006). Due to poor healthcare services among indigenous peoples, the prevalent rate of preventable and endemic diseases tends to be higher among them compared to non-indigenous populations (Ohenjo et al., 2006). Thus, there is high incidence of measles among children of indigenous peoples, reported cases of leprosy and yaws as well as susceptibility to other infectious diseases. While there is no evidence to show that HIV prevalence among indigenous peoples are higher than other members of society, there seems to be evidence of poor or lack of HIV-related goods and services. To address these challenges, the authors recommend that African governments must respect indigenous peoples' rights to self-determination, participation and resources (Ohenjo et al., 2006). It is further suggested that programmes and policies to address the health needs of indigenous peoples must necessarily involve them so as to ensure a positive outcome.

Another study has shown that in Rwandan Twa households the prevalence of poor sanitation and lack of safe, potable water were respectively seven times and two times higher than for the national population (Minority Rights Group [MRG], 2013). Also, in Tanzania, efforts to reduce mother-to-child transmission of HIV among pastoralists were hampered by the fact that the campaign was issued in the dominant language-Swahili. ${ }^{20}$ Across the world, policy-makers often grapple with the challenge of realising access to healthcare services for vulnerable and marginalised groups such as indigenous peoples. This reflects the complexity of our world and requires pragmatic actions from policy-makers. In describing the 
challenges indigenous peoples encounter in accessing health careservices in Namibia, the UN Special Rapporteur on the rights of indigenous peoples (2013, pp. 69-70) has noted as follows:

San and other indigenous peoples have been denied medical treatment or expelled from hospitals because they are unable to pay for services. San mothers in the Divundu area informed the Special Rapporteur that they had been forced out of hospital facilities the same day they gave birth because they could not afford care. The remote character of many San and Himba groups often aggravates their vulnerabilities with regard to health and health care ... Numerous San community members from different villages told the Special Rapporteur that it is not uncommon for individuals to die while being transported long distances to receive healthcare services. ${ }^{21}$

This situation is not peculiar to Namibia or Africa, and it reflects the overall challenges indigenous peoples encounter in many African countries. A recent study by Negin, Aspin, Gadsden, and Reading (2015) in four developed countries - Canada, United States, Australia and New Zealand - has shown that HIV prevalence in indigenous communities is relatively high due largely to high poverty rate coupled with discrimination and historical neglect of health needs of indigenous peoples. Yet policy-makers across Africa have not paid enough attention to the health needs of indigenous peoples. While evidence abounds of the challenges and human rights violations facing indigenous people, paucity of research exists on the nexus between human rights and health needs of indigenous populations in Africa. The question may be asked: Is there any utility in adopting a rights-based approach to access to healthcare services for indigenous peoples in Africa? This question becomes more important when it is considered that African governments have ratified human rights instruments that require them to secure the right to health of vulnerable and marginalised groups such as indigenous peoples. A rights-based approach to health requires adherence to the elements of availability, accessibility, acceptability and quality as well as accountability and effective implementation of laws and policies by governments (Gruskin, Bogecho, \& Ferguson, 2010). It further requires that African governments should adopt deliberate and targeted policies and programmes that will address the specific needs of indigenous peoples in the region.

A report by the African Commission's Working Group on Indigenous Populations/Communities (2005, pp. 52-54) notes as follows:

The Batwa in Rwanda, Burundi and Uganda are severely discriminated in terms of healthcare due to poverty and marginalisation. The Batwa have very limited access to primary health care and they do not obtain any medical care, either for themselves or for their children. Malnutrition rates and health statistics are generally poor in the Great Lakes region and in such circumstances, the Batwa - with neither land nor other resources with which to feed themselves - are among the first to suffer ... 
The same picture repeats itself for other countries in the Great Lakes Region. For instance in Congo where, in comparison with other village inhabitants, the Babendjelle from the north Congo forest suffer more from yaws, jiggers, leprosy and conjunctivitis. The mortality rate from measles is five times higher amongst the Babendjelle than the Bantu. Under- 5 mortality is $27 \%$ among the Babendjelle compared with $18 \%$ among Bantu children. The Babendjelle are nicknamed out of prejudice (la viande quiparle the animal that can speak) and so do not receive the same treatment. This leads the health staff to discriminate against sick Babendjelle. For example, their consultation takes place after all Bantu have been dealt with, and they are refused appropriate treatment.

The report identifies some challenges and barriers to healthcare services for indigenous groups in African countries. It highlights that infant and maternal mortality rates are usually higher among indigenous groups than non-indigenous populations. Incidence of malaria, malnutrition, lack of water and sanitation, unhygienic environment is said to be very high among indigenous peoples. Some of the barriers to healthcare services for indigenous groups include high rates of poverty, lack of transportation, inability to afford treatment, discrimination, lack of information among indigenous groups. The conclusion that can be drawn from this report is that African governments have yet to prioritise the health needs of indigenous populations in the region.

\section{Measuring states' obligations to realise the right to health of indigenous peoples}

International and regional human rights instruments on the right to health (already discussed above), often obligate states to respect, protect and fulfil this right. It should be noted that the enjoyment of the right to health is dependent on respect for other rights such as privacy, dignity, non-discrimination and life. In relation to indigenous peoples' right to health, the duty to respect implies that states must desist from all act that may interfere with the enjoyment of this right. A state will be in breach of this obligation if, for instance, it embarks on systematic exclusion of indigenous populations from healthcare service through policies and programmes. Such exclusion will not only result in unfair discrimination but will also undermine the dignity of indigenous peoples. The Permanent Forum on Indigenous Issues has noted in one of its reports that consulting with indigenous peoples before policies or decisions are made should be viewed as a fundamental right and not a favour. ${ }^{22}$

A state will be held to be in breach of the duty to protect if it fails to control the activities of third parties that may impair this right. For instance, failure to prevent healthcare workers in public and private hospitals from embarking on discriminatory practices against indigenous peoples will amount to breach of the duty to protect. In the SERAC case, the African Commission found that the Nigerian government was in breach of its obligation to protect the rights to life, water, food and health of the Ogoni people for failing to regulate the

activities of multi-national oil companies. 23 The duty to fulfil is breached if the health needs of indigenous peoples are grossly underfunded or if the state fails to invest in training of skilled healthcare providers that can provide good services to indigenous peoples. In 
determining whether a state has failed to meet its obligations to realise the rights to health of indigenous peoples, the essential elements of this right as developed by the CESCR must be taken into consideration. The discussion that follows relates to how these elements apply to indigenous peoples in Africa.

Availability: The CESCR stipulates that healthcare services must be available in sufficient quantity for all, especially vulnerable and marginalised groups. This implies that hospitals, clinics and healthcare providers must be available in sufficient numbers for vulnerable and marginalised groups such as indigenous peoples. However, studies have shown that indigenous populations' health needs are largely unmet in many African countries (MRG, 2013). This in turn has led to poor health indicators among indigenous peoples. Experience has shown that healthcare services and facilities are usually unavailable for indigenous peoples due to lack of priority by governments (MRG, 2013). This may indicate failure on the part of African governments to realise the right to health of indigenous peoples. The obligation to ensure available healthcare services for indigenous peoples is heightened when it is considered that children, women and persons with disabilities among indigenous populations are likely to be worst affected by this situation.

Accessibility: This requires African governments to take into cognisance four important elements, including non-discrimination, information accessibility and physical and economic accessibility of vulnerable and marginalised groups, in the realisation of healthcare services for indigenous peoples. The report of the Special Rapporteur on indigenous populations has identified various challenges hindering access to health care for indigenous peoples. ${ }^{24}$ These include poverty, cost of treatment, distance of healthcare facilities from where indigenous peoples live, lack of transportation, lack of information due to language barrier and discriminatory attitudes of healthcare providers. All these challenges will no doubt be in contravention of the need to ensure accessible healthcare services for indigenous peoples. It may be an indication of failure of African states to fulfil the right to health of indigenous peoples. It should be noted that the obligation to ensure healthcare services in a non-discriminatory manner constitutes one of the minimum core contents of the right to health. In its concluding observations to Rwanda, the CESCR has noted with concern 'the persistence of stereotypes against the 'Batwa' population and the discrimination they continue to face preventing them from fully enjoying' their socioeconomic rights, particularly access to healthcare services. ${ }^{25}$ The Committee urged the Rwandan government to take appropriate measures to 'firmly combat stereotypes, stigma and discrimination against and marginalization of Batwa' and ensure that all their rights are fully realised. Therefore, African governments cannot hide under the excuse of a lack of resources for failing to fulfil this obligation.

Acceptability: One of the identified challenges indigenous peoples encounter in relation to health-care services has to do with the appropriateness or otherwise of such services. Often, African governments tend to lay emphasis on ensuring access to western medical services and hardly promote traditional medicines which may be suitable to the needs of indigenous 
peoples (United Nations, 2014). Moreover, experience has shown that healthcare providers in public hospitals hardly take into consideration the traditions and cultures of indigenous peoples when providing services. It has also been found that where indigenous population also belongs to the minority group, language barrier can impede their ability to seek healthcare services (International Labour Organisation \& African Commission on Human and Peoples' Rights, 2009). Unfortunately, most public hospitals in Africa do not provide interpreter services to address this barrier. The Canadian Supreme Court in Eldridge v Attorney General and others has held that failure of the government to ensure sign interpreter for persons with impaired sight and hearing will amount to a violation of the right to equality and non-discrimination guaranteed in the Charter of Rights. ${ }^{26}$ Although this case applies to persons with disabilities the reasoning exemplifies that government must pay special attention to the need of vulnerable and marginalised groups such as indigenous populations.

Quality healthcare services: This requires the government to allocate adequate resources that will ensure delivery of efficient, timely and satisfactory healthcare services. Public healthcare services in many African countries are largely underfunded. In addition, remuneration for healthcare providers tend to be poor and uncompetitive compared to the private sector. Thus, healthcare providers tend to seek greener pastures either overseas or in private sector. This has implications for the quality of health services in public hospitals in Africa since it may lead to shortages of skilled healthcare providers. While this is likely to impact on the right to health of the people in general, its implications can be more devastating for indigenous populations who are already disadvantaged and deprived of other amenities. The CESCR in its concluding observations to Burundi has noted that disadvantaged or marginalised individuals and groups, in particular, the Batwa indigenous peoples continue to encounter obstacles in accessing health services. ${ }^{27}$ It expressed deep concern about the quality and availability of healthcare services, especially in remote rural areas. Thus, it urged the Burundian government to allocate sufficient resources to the health sector to meet the needs of disadvantaged and marginalised groups.

\section{Conclusion}

It is clear that for African governments to meet the health needs of indigenous population in the region, a more pragmatic approach grounded in respect for human rights is essential. Such an approach must recognise the rights to dignity and non-discrimination of indigenous peoples. More importantly, governments must review budgetary allocations to the health needs of indigenous peoples in order to address inequities in provision of services (Yamin \& Norheim, 2014). The current approach in many African states where issues relating to the needs of indigenous peoples are treated with levity is not acceptable. African governments must strive through adoption of appropriate measures to remove barriers to healthcare services for indigenous peoples. In this regard, they may be required to provide free medical services for indigenous populations and ensure that well-trained health providers that can speak the languages of indigenous peoples are recruited. At the same time, African governments must develop laws, policies and programmes that will facilitate 
access to healthcare services for indigenous peoples. This should include access to traditional medicines that meets the specific needs of indigenous population. ${ }^{28}$ Involving indigenous peoples in the development of such policies and programmes is crucial and must form the fulcrum of all measures adopted to realise access to healthcare services for them. ${ }^{29}$ The UN Expert Mechanism on the Rights of Indigenous Peoples has noted that:

Health is an indispensable component of indigenous peoples' very existence, survival and entitlement to live in dignity and determine their own futures. States should therefore seek the free, prior and informed consent of indigenous peoples before implementing laws, policies or programmes affecting their health or health rights. (Expert Mechanism on the Right of Indigenous Peoples, 2016)

In its landmark decision of Kichwa Indigenous People of Sarayaku v. Ecuador, the InterAmerican Court has held that that the obligation of States to consult with indigenous peoples is now a general principle of international law. 30

Access to healthcare services for indigenous peoples should not be viewed as a charity or privilege; rather it should be seen as a human rights imperative. 


\section{Notes}

1. United Nations, A new global partnership: Eradicate poverty and transform economies through sustainable development; The report of the high level panel of eminent persons on the post-2015 sustainable development agenda, New York, United Nations, 2013, Executive Summary. Retrieved from www.un.org/sg/management/ pdf/HLP_P2015_Report.pdf.

2. Universal declaration of human rights adopted by the United Nations General Assembly in Paris on 10 December 1948 General Assembly resolution 217 www.un.org/en/universaldeclaration-human-rights.

3. World Health Organization (2007).

4. Report of the African Commission's Working Group of Experts on Indigenous Populations/Communities 2005, p. 20. Retrieved from http://www.iwgia.org/iwgia_files_publications_files/African_Commission_book. pdf.

5. Universal Declaration of Human Rights adopted by the United Nations General Assembly in Paris on 10 December 1948 General Assembly resolution 217 Retrieved from www.un.org/en/universal-declaration-human-rights.

6. International Covenant on Economic, Social and Cultural Rights, adopted on 16 December 1966; GA Res 2200 (XXI), UN Doc. A/6316 (1966) 993 UNTS 3 (entered into force 3 January 1976).

7. Convention on the elimination of all forms of discrimination against women GA Res 54/180 UN GAOR 34 $4^{\text {th }}$ Session Supp. No. 46 UN Doc. A/34/46 1980 (article 12).

8. Convention on the Rights of the Child GA Res 25 (XLIV), UN GAOR Supp. No. 49 UN Doc. A/RES/44/25 1989 (article 24).

9. Convention on the Rights of Persons with Disabilities adopted in 2006 A/RES/61/106 (article 25).

10. UN Committee on Covenant on Economic, Social and Cultural Rights: The Right to the Highest Attainable Standard of Health (article 12 of the Covenant), 11 August 2000, E/C.12/2000/4. Retrieved from http:// www.refworld.org/docid/4538838do.html.

11. As above paras 8-12.

12. UN Committee on Covenant on Economic, Social and Cultural Rights: Right to sexual and reproductive health.

13. The United Nations Declaration on the Rights of Indigenous Peoples (UNDRIP) $\begin{array}{llllll}\text { adopted } & \text { in } & 13 & \text { September } & \text { 2007. } & \text { Retrieved }\end{array}$ www.un.org/esa/socdev/unpfii/documents/DRIPS_en.pdf.

14. ILO Indigenous and Tribal Peoples' Convention 1989 (No. 169) adopted during the 76th ILC session (27 June 1989).

15. See Establishment of the UN Permanent Forum on indigenous Issues Economic and Social Council (ECOSOC) Resolution 2000/2022.

16. African Charter on Human and Peoples' Rights OAU Doc CAB/LEG/67/3/Rev 5, adopted by the Organisation of African Unity, 27 June 1981, entered into force 21 October 1986.

17. African Charter on the Rights and Welfare of the Child, OAU Doc CAB/LEG/24.0/49 (1990) (entered into force 29 November 1999).

18. Adopted by the 2nd Ordinary Session of the African Union General Assembly in 2003 in Maputo CAB/LEG/66.6 (2003) entered into force 25 November 2005. 
19. Established by the African Commission on Human and Peoples' Rights with the adoption of Resolution 51 at the 28th Ordinary Session (Cotonou, Benin - 23 October to 6 November 2000).

20. WHO Factsheet on health of Indigenous Peoples.

21. See the Report of the UN Special Rapporteur on indigenous peoples on Namibia 2013 A/HRC/24/41/Add.1, 25 June 2013 paras 68-69.

22. See the Report of Permanent Forum on Indigenous Peoples on tenth anniversary of the United Nations Declaration on the Rights of Indigenous Peoples: Measures taken to implement the declaration of the sixteenth session New York, 24 April-5 May 2016 E/C.19/2017/4.

23. Social and Economic Rights Action Centre (SERAC) and another v Nigeria (2001) AHRLR 60 (ACHPR 2001).

24. The Report of the UN Special Rapporteur on indigenous peoples on Namibia 2013 A/HRC/24/41/Add.1, 25 June 2013 paras 68-69.

25. CESCR Concluding observation to Rwanda adopted during the 28th Meeting held 17 MAY 2013 E/C.12/RWA/ CO/2-4.

26. Eldridge v British Columbia (Attorney-General) 1997151 DLR (4th) 577.

27. CESCR Concluding Observations to Burundi adopted during the 78th meeting, held on 9 October 2015 E/C.12/ BDI/CO1/1.

28. See article 23 of the United Nations Declaration on the Rights of Indigenous Peoples (UNDRIP) adopted in 13 September 2007. Retrieved from www.un.org/esa/socdev/unpfii/documents/DRIPS_en.pdf.

29. See articles 22 and 29 of ILO Convention 169.

30. Cited in Sieder (2016).

\section{Disclosure statement}

No potential conflict of interest was reported by the author. 


\section{References}

African Commission on Human and Peoples' Rights. (2005). Report of the working group of experts on indigenous populations/communities. Banjul: African Commission.

Ako, R. T., \& Oluduro, O. (2014). Identifying beneficiaries of the UN indigenous peoples' partnership (UNIPP): The case for the indigenes of Nigeria's Delta region. African Journal of International and Comparative Law, 22, 369-398. doi.org/10.3366/ajicl.2014.0099

Gruskin, S., Bogecho, D., \& Ferguson, L. (2010). Rights-based approaches' to health policies and programs: Articulations, ambiguities, and assessment. Journal of Public Health Policy, 31, 129-145. doi:10.1057/jphp.2010.7

International Labour Organisation and African Commission on Human and Peoples' Rights. (2009). Overview of research project on the constitutional and legislative protection of the rights of indigenous peoples in Africa. Geneva: International Labour Organisation.

Minority Rights Group. (2013). International state of the world's minorities and indigenous peoples: Addressing health inequities in the post-2015 development agenda. London: Author.

Negin, J., Aspin, C., Gadsden, T., \& Reading, C. (2015). HIV among indigenous peoples: A review of the literature on HIV-related behaviour since the beginning of the epidemic. AIDS Behaviour, 19, 1720-1734. doi:10.1007/s10461- 015-1023-0

Ohenjo, N., Willis, R., Jackson, D., Nettleton, C., Good, K., \& Mugarura, B. (2006). Health of indigenous peoples in Africa. Lancet, 367, 1937-1946. doi:10.1016/So1406736(06)68849-1

Sieder, R. (2016). Indigenous peoples' rights and the law in Latin America. In D. Short, \& C. Lennx (Eds.), Handbook of indigenous peoples' rights (pp. Chap. 27, 414-423). London: Routledge.

UN Expert Mechanism on the Rights of Indigenous Peoples. (2016). Right to health and indigenous peoples with focus on children and youth. New York, NY: United Nations.

United Nations. (2015). A New global partnership: Eradicate poverty and transform economies through sustainable development: The report of the high level panel of eminent persons on the post-2015 sustainable development agenda. New York, NY: United Nations.

United Nations Inter-Agency Support Group on Indigenous Peoples' Issues. (2014). The health of indigenous peoples. New York, NY: United Nations.

UN Special Rapporteur on the right of everyone to the enjoyment of the highest attainable standard of physical and mental health. (2006). Report on the right to an effective integrated system accessible to all and human rights based approach to health indicators. Geneva: United Nations.

UN Special Rapporteur on the rights of Indigenous peoples. (2013). Report on the situation of indigenous peoples in Namibia. Geneva: United Nations.

UN Special Rapporteur on the right to everyone to the enjoyment of the highest attainable standard of physical and mental health. (2016). Report on the link between the 2030 agenda for sustainable development and the sustainable development goals and the right to health. Geneva: United Nations. 
World Health Organization. (2007). Health of indigenous peoples (Factsheet No. 326). Retrieved November 10, 2016, from http://www.who.int/mediacentre/factsheets/fs326/en/

Yamin, A. E., \& Norheim, O. F. (2014). 'Taking equality seriously': Applying human rights frameworks to priority setting in health. Human Rights Quarterly, 36, 296-324. 